\title{
Editorial
}

\section{Iain D. Campbell - A revolutionary protein NMR spectroscopist}

\author{
Parvez I. Haris * \\ Faculty of Health \& Life Sciences, De Montfort University, Leicester, United Kingdom
}

Iain D. Campbell (Fig. 1) born in Perth in 1941 was raised in a small Scottish village called Blackford. At school he discovered that he had greater aptitude for science and maths than other subjects. It is therefore not surprising that he chose to study Physics at St Andrews University for his BSc (1959) and $\mathrm{PhD}$ (1966) degrees. In 1967 he was recruited by Sir Rex Richards FRS at the Physical Chemistry Laboratory (PCL) at Oxford University. In 1971 he took on the challenge to construct the best nuclear magnetic resonance (NMR) spectrometer of that time. He was based at the Department of Biochemistry working with colleagues in the Oxford Enzyme Group. Application of NMR spectroscopy in Biochemistry was just beginning in early 1970s. These were exciting times, as Iain and his colleagues exploited this emerging technique to study complex systems including macromolecules as well as small molecules

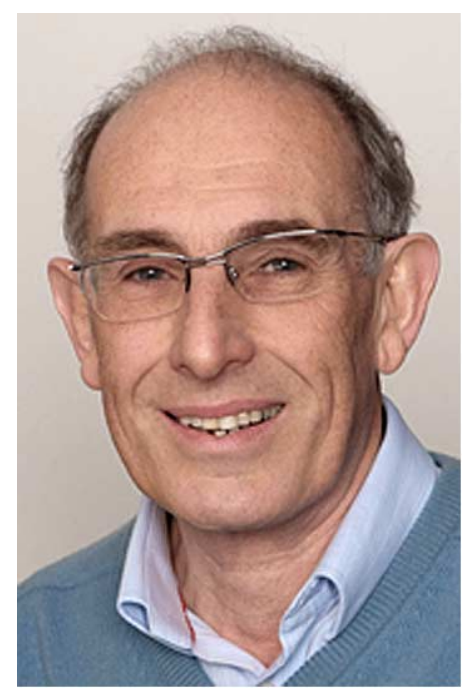

Fig. 1. Professor Iain D. Campbell FRS is currently Emeritus Professor of Biochemistry at Oxford University. (Colors are visible in the online version of the article; http://dx.doi.org/10.3233/BSI-130056.)

\footnotetext{
*Address for correspondence: Faculty of Health \& Life Sciences, De Montfort University, The Gateway, Leicester, LE1 9BH, United Kingdom. E-mail: pharis@dmu.ac.uk.
} 


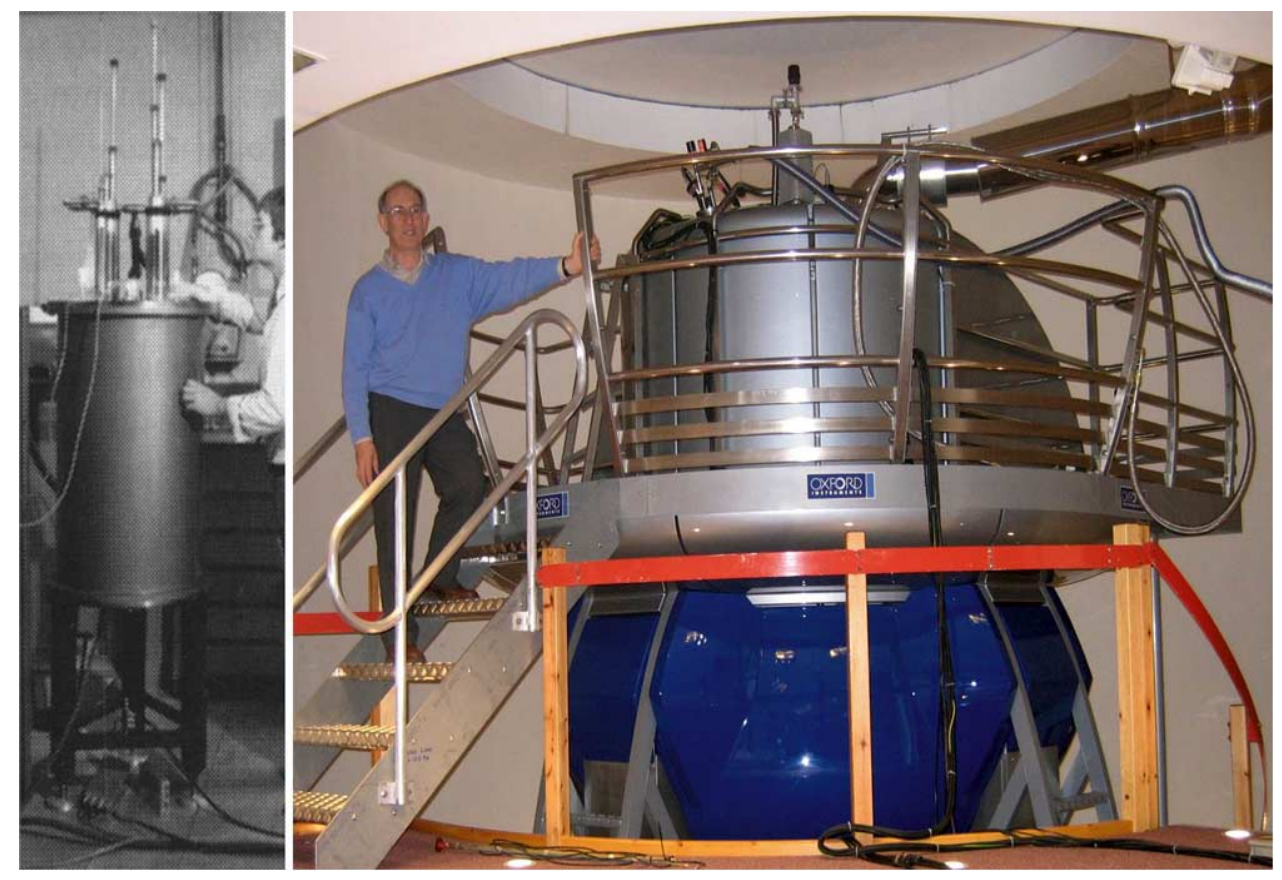

Fig. 2. Left: Picture of the early $270 \mathrm{MHz}$ NMR spectrometer that Iain Campbell used at Oxford (photograph taken in 1971). Right: Iain standing next to a $950 \mathrm{MHz}$ NMR spectrometer at Oxford (photograph taken in 2008 ). (Colors are visible in the online version of the article; http://dx.doi.org/10.3233/BSI-130056.)

in cells and tissues. Figure 2 shows the first $270 \mathrm{MHz}$ NMR instrument Iain used back in 1970. Technology has moved on since then and he can be seen standing proudly next to a powerful $950 \mathrm{MHz} \mathrm{NMR}$ spectrometer in a photograph taken in $\sim 2008$.

At Oxford, he was influenced by many prominent scientists including Rex Richards, Bob Williams, Raymond Dwek and Chris Dobson (see Fig. 3). One of Iain's major achievements was the elucidation of the three-dimensional structure of epidermal growth factor (EGF) in aqueous solution using NMR spectroscopy [4]. This was one of the first proteins to have its NMR structure determined and it can be considered as a landmark achievement in structural biology. It provided important insights into the role of EGF domains in a large range of other proteins. It would not be incorrect to state that the domain-bydomain approach to determining the structure of complex proteins by NMR spectroscopy was pioneered by Iain Campbell. Thanks to this approach, we now have a better understanding of the structure-function relationships of many proteins that play a pivotal role in diverse processes including immune response, tissue repair and embryonic development. This is paving the way for a better understanding of disease processes including cancer and the development of new drugs.

I was always impressed by Iain ever since I was a PhD student in London. I never missed an opportunity to listen to him speaking at conferences. Iain is not only an outstanding research scientist, but he is also a distinguished educationalist and a kind human being. Although he predominantly used NMR spectroscopy for most of his research, he believes that no single technique can provide information on all aspects of protein structure-function relationships which is evident from the books he has written. As a graduate student during the 1980s, I personally benefited from reading his book entitled Biological Spectroscopy which he co-authored with Raymond Dwek [3]. More recently he has written another book [1] that will no doubt benefit another generation of graduate students and others interested in biophysical 


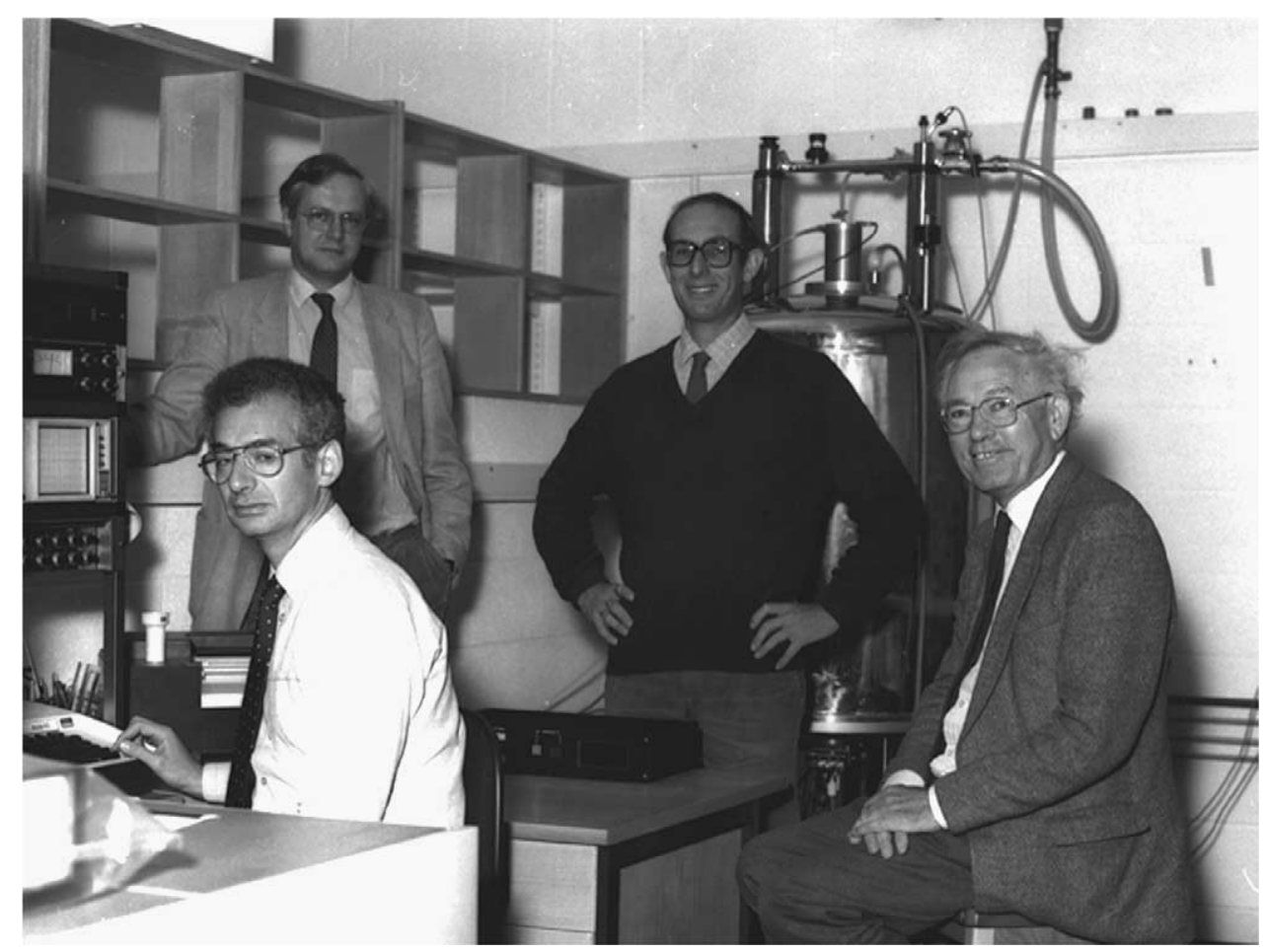

Fig. 3. Photograph of Iain Campbell (wearing a jumper) with some of his colleagues from Oxford University, Raymond Dwek, Chris Dobson and Bob Williams (photograph taken in 1986).

techniques. Despite his busy schedule at Oxford, Iain kindly accepted my invitation to write a thought provoking article that reflects his views on the evolution of protein NMR spectroscopy [2]. It is an important and a timely article from one of the pioneers of biological NMR spectroscopy who played a key role in the evolution of this powerful spectroscopic method.

\section{References}

[1] I.D. Campbell, Biophysical Techniques, Oxford Univ. Press, 2012.

[2] I.D. Campbell, The evolution of protein NMR, Biomedical Spectroscopy and Imaging 2 (2013), 245-264 (this issue).

[3] I.D. Campbell and R.A. Dwek, Biological Spectroscopy, Benjamin/Cummings Publishing Company, 1984.

[4] R.M. Cooke, A.J. Wilkinson, M. Baron, A. Pastore, M.J. Tappin, I.D. Campbell, H. Gregory and B. Sheard, The solution structure of epidermal growth factor, Nature 327 (1987), 339-341. 